\title{
Aprendendo síntese proteica de forma interativa e lúdica: O Desafio da Síntese Proteica
}

\section{Synthesis in an interactive and playful way: The Challenge of Protein Synthesis}

\author{
Patrícia Matos de Almeida ${ }^{1,3}$, Diego Soares Carvalho ${ }^{2,3}$, Cláudio Alves Pereira ${ }^{3}$ \\ ${ }^{1}$ Secretaria Municipal de Educação (SME-SP), São Paulo, Brasil. \\ ${ }^{2}$ Instituto Federal de Educação, Ciência e Tecnologia de Rondônia (IFRO) Campus Colorado do Oeste, Brasil. \\ ${ }^{3}$ Instituto Federal de Educação, Ciência e Tecnologia de Minas Gerais (IFMG) Campus Avançado Arcos, Brasil. \\ 1 e-mail: patyy_pma@hotmail.com
}

\begin{abstract}
The objective of this work is to provide an easy access and low-cost pedagogical tool to Biology teachers for use in educational institutions that do not have educational kits. In order to reach this aim, researchers propose a playful educational strategy that prioritizes playfulness in the study of "protein synthesis" content, which is planned for High School students. Regarding the complexity of the "protein synthesis" issue and also the difficulties found when working on this content, the proposed pedagogical tool appears as an opportunity to make it more understandable to students, contributing in the transposing process of the abstraction and bringing the study to the classroom as a practice. The proposal includes processes in which students participate in the creation of the game, and later, they start the dynamics of it. We believe that the utilization of this game has the potential applicability as a pedagogical tool, serving as an alternative option to the traditional class model, and it also follows the direction of an active and collaborative teaching, in order to enhance the learning process.
\end{abstract}

Keywords: protein synthesis; game; didactic material.

\section{Resumo}

O objetivo desse trabalho é fornecer uma ferramenta pedagógica lúdica, interativa, de fácil confecção e baixo custo aos professores de Biologia para uso em instituições de ensino que não disponham de kits didáticos. Para isso, os pesquisadores propõem uma estratégia educativa que prioriza a ludicidade no estudo do conteúdo de síntese proteica planejada para o Ensino Médio. Entendendo a complexidade do conteúdo de Síntese de Proteínas e das dificuldades impostas ao se trabalhar esse conteúdo, a ferramenta pedagógica proposta vem ao encontro de torná-lo mais compreensível aos alunos, contribuindo no processo de transposição do campo da abstração e trazendo o estudo para a prática na sala de aula. A proposta inclui processos em que os alunos participam da confecção do jogo e, posteriormente, iniciam a dinâmica do jogo. Acreditamos que a confecção e utilização desse jogo tem o potencial de aplicabilidade como ferramenta pedagógica, servindo como uma alternativa ao modelo tradicional de aula e aponta para um ensino ativo e colaborativo, favorecendo uma aprendizagem significativa.

Palavras-chave: Palavras-chave: Síntese Proteica; Jogo; Material Didático. 


\section{Ficha da atividade}

\begin{tabular}{|c|c|}
\hline Título & $\begin{array}{l}\text { Aprendendo síntese proteica de forma interativa e lúdica: O Desafio da Síntese } \\
\text { Proteica }\end{array}$ \\
\hline Categoria: & Jogo didático \\
\hline Público-alvo: & Alunos do ensino médio \\
\hline $\begin{array}{l}\text { Disciplinas } \\
\text { relacionadas: }\end{array}$ & Biologia e Química. \\
\hline $\begin{array}{l}\text { Conteúdos } \\
\text { abordados }\end{array}$ & Código genético e síntese de proteínas \\
\hline $\begin{array}{l}\text { Objetivos } \\
\text { educacionais }\end{array}$ & $\begin{array}{l}\text { Utilizar de metodologia lúdica e interativa para revisar o conteúdo abordado } \\
\text { através de aulas teóricas; evidenciar a compreensão dos alunos e as possíveis } \\
\text { lacunas no entendimento do tema em questão; estimular o interesse dos alunos; } \\
\text { possibilitar que o professor e os alunos trabalhem os conteúdos de uma forma } \\
\text { mais dinâmica e atrativa, uma vez que ambos trabalharão na confecção do jogo } \\
\text { didático "o aprender fazendo"; favorecer o envolvimento e o engajamento dos } \\
\text { estudantes com a temática, favorecendo assim, a compreensão do fluxo da } \\
\text { informação gênica através do processo de tradução de nucleotídeos em } \\
\text { aminoácidos e estes em proteínas. }\end{array}$ \\
\hline $\begin{array}{l}\text { Duração } \\
\text { estimada para } \\
\text { confecção }\end{array}$ & 90 minutos \\
\hline $\begin{array}{l}\text { Duração } \\
\text { estimada de jogo }\end{array}$ & 40 minutos \\
\hline $\begin{array}{l}\text { Materiais } \\
\text { utilizados }\end{array}$ & $\begin{array}{l}\text { Placa de E.V.A. várias cores; Fita de cetim (ou outro tecido); Canetas hidrocor } \\
\text { variadas; Tesoura e caixa grande de papelão. }\end{array}$ \\
\hline Justificativa & $\begin{array}{l}\text { O fluxo da informação gênica, a compreensão do código genético e a síntese de } \\
\text { proteínas são conhecimentos indispensáveis à compreensão da Biodiversidade e } \\
\text { fisiologia dos organismos. A abordagem didática adotando jogos didáticos } \\
\text { permite aos discentes sair do campo abstrato e, de forma lúdica, auxiliar na } \\
\text { compreensão dos conteúdos que apresentam maior grau de dificuldade. O jogo } \\
\text { auxilia na integração desses conceitos, a fim de revisar ou demonstrar e, de } \\
\text { forma motivante e lúdica, alcançar a aprendizagem mais concreta do tema } \\
\text { estudado. }\end{array}$ \\
\hline
\end{tabular}




\title{
1 Introdução
}

É recorrente o relato de alunos que apresentam certa aversão ao estudar Biologia, apresentando como algumas justificativas o grande número de termos diferentes do seu vocabulário cotidiano e cuja significação Ihes exige alto grau de abstração [1-2]. 0 assunto abordado pelos pesquisadores na proposta deste jogo se mostra como complexo e, pelos relatos dos professores de Biologia do Ensino Médio, o conteúdo Síntese Proteica se constitui como um planejamento desafiador [2-6]; como tornar o ensino dinâmico e que produza efetiva aprendizagem nos alunos? No sentido de tornar o ensino do conteúdo de síntese proteica mais dinâmico e interativo, estamos propondo neste artigo o uso do jogo didático supracitado.

Há relatos na literatura que demonstram a eficácia dos jogos didáticos como uma ferramenta metodológica exitosa no ensino de Ciências e Biologia [7-10]. Nesse sentido, é possível que as lacunas deixadas pelo método tradicional de ensino que prevalece no processo de transmissão-recepção de conhecimentos sejam preenchidas pelo trabalho de confecção e aplicação do jogo, estratégia que poderá favorecer a construção do conhecimento pelo próprio aluno, indo ao encontro das metodologias ativas colaborativas [11-15].

Além da possibilidade de se trabalhar conteúdos complexos de forma lúdica e divertida, o jogo didático pode permitir que sejam trabalhadas outras competências cognitivas, sociais e afetivas que estão além dos conteúdos de Biologia, como: afeição, socialização, trabalho em equipe favorecendo a colaboração, motivação e criatividade [16-17].

Segundo Almeida (2004, p.22) [11]:

\begin{abstract}
“... jogos orientados podem ser feitos com propósitos claros de promover o acesso à aprendizagem de conhecimentos específicos como: matemáticos, linguísticos, científicos, históricos, físicos, estéticos, morais e etc. E outro propósito é ajudar no desenvolvimento cognitivo, afetivo, social, físico motor, linguístico e na construção da moralidade (em seus valores)".
\end{abstract}

Neste contexto, a utilização de jogos didáticos apresenta o potencial de promover um ambiente motivador que é fundamental para melhorar o processo de ensino e aprendizagem, dinamizando o processamento cognitivo de informações, por estreitar relações entre os aspectos lúdicos e cognitivos [18]. Tendo em vista a importância do uso de jogos didáticos em sala de aula, o presente estudo tem o objetivo de apresentar uma proposta metodológica lúdica, interativa e colaborativa e de fácil confecção para trabalhar o conteúdo de síntese de proteínas e o código genético nas aulas de Biologia do ensino médio.

O que torna essa proposta diferenciada das demais propostas publicadas é a facilidade de compreensão e confecção, uso de materiais de fácil acesso e baixo custo finan- 
ceiro e a sua maior novidade é a dinâmica de interação do jogo que permite um número grande de participantes com atividades específicas a serem desenvolvidas.

Tendo em vista o baixo custo financeiro, dinâmica bastante interativa e o envolvimento de vários jogadores, a sua confecção e utilização se mostram especialmente recomendadas para os professores de instituições públicas de ensino, dada a limitada disponibilidade de recursos financeiros para aquisição de kits didáticos.

\section{Desenvolvimento e aplicação}

\subsection{Confecção do material}

As sequências de nucleotídeos de DNA apresentadas nas figuras 1, 2 e 3 abaixo, representam os genes que formarão os diferentes RNAm. Cada equipe deverá receber impresso em folha de sulfite A4 a sequência de nucleotídeos do seu gene. A fita molde do DNA está marcada com a cor vermelha.

\section{Equipe -1 - Gene fictício da insulina}

DNA $\Rightarrow$ 5' ATG TTT GTA GAT GAC TAT AAC GAA GTG CGC TAA GGC GAT 3’

3' TAC AAA CAT CTA CTG ATA TTG CTT CAC GCG ATT CCG CTA 5

Figura 1 - Representação do gene fictício da insulina. Fonte: Elaborada pelos autores.

\section{Equipe - 2 - Gene fictício da hemoglobina}

DNA $\Longrightarrow \quad$ 5' ATG GTA GAT ATG ACG ATA TTG CTT CAC GCG TAG GGC GAT 3' 3' TAC CAT CTA TAC TGC TAT AAC GAA GTG CGC ATC CCG CTA 5'

Figura 2 - Representação do gene fictício da hemoglobina. Fonte: Elaborada pelos autores.

\section{Equipe - 3 - Gene fictício do hormônio do crescimento (GH)}

\section{DNA $\Longrightarrow \quad$ 5' ATG ACT CAC CGA GCG CGA AGC TGA AAA GTA TGA TTC CTA 3'} 3' TAC TGA GTA GCT CGC GCT TCG ACT TTT CAT ACT CCG CTA 5'

Figura 3 - Representação do gene fictício do hormônio do crescimento. Fonte: Elaborada pelos autores.

Os RNAs mensageiros (RNAm) deverão ser confeccionados em fita de cetim com 2,3 m de comprimento. Por meio da fita molde de DNA que a equipe receberá, os seus participantes terão que fazer a transcrição do gene e formar o RNAm, escrevendo com canetão as trincas de nucleotídeos (códons) referentes à sequência do gene na fita de cetim. Coloque na fita 5' e inicie a transcrição, deixe cada trinca na fita dividida em um com- 
primento de $15 \mathrm{~cm}$ e $2 \mathrm{~cm}$ de espaçamento entre cada trinca. As figuras 4, 5 e 6 apresentam os RNAm que as equipes terão que "sintetizar".

\section{Equipe - 1 Sequência do RNAm}

5' AUG UUU GUA GAU GAC UAU AAC GAA GUG CGC UAA GGC GAU 3'

Figura 4 - Representação do RNAm transcrito a partir do gene da insulina. Fonte: Elaborada pelos autores.

\section{Equipe - 2 Sequência do RNAm}

\section{5’ AUG GUA GAU UAC ACG AUA UUG CUU CAC GCG UAG GGC GAU 3'}

Figura 5 - Representação do RNAm transcrito a partir do gene da hemoglobina. Fonte: Elaborada pelos autores.

\section{Equipe - 3 Sequência do RNAm}

\section{5' AUG ACU CAU CGA GCG CGA AGC UGA AAA GUA UGA GGC GAU 3'}

Figura 6 - Representação do RNAm transcrito a partir do gene do hormônio do crescimento. Fonte: Elaborada pelos autores.

Os RNAs transportadores (RNAt) devem ser confeccionados em acetato-vinilo de etileno (EVA), com $15 \mathrm{~cm}$ de comprimento por $15 \mathrm{~cm}$ de largura. A partir da fita de RNAm que a equipe formará, cada aluno representante do RNAt terá que pegar o seu RNA e escrever a sequência complementar ao códon, sendo este o anticódon, conforme representado na Figura 7 abaixo. 


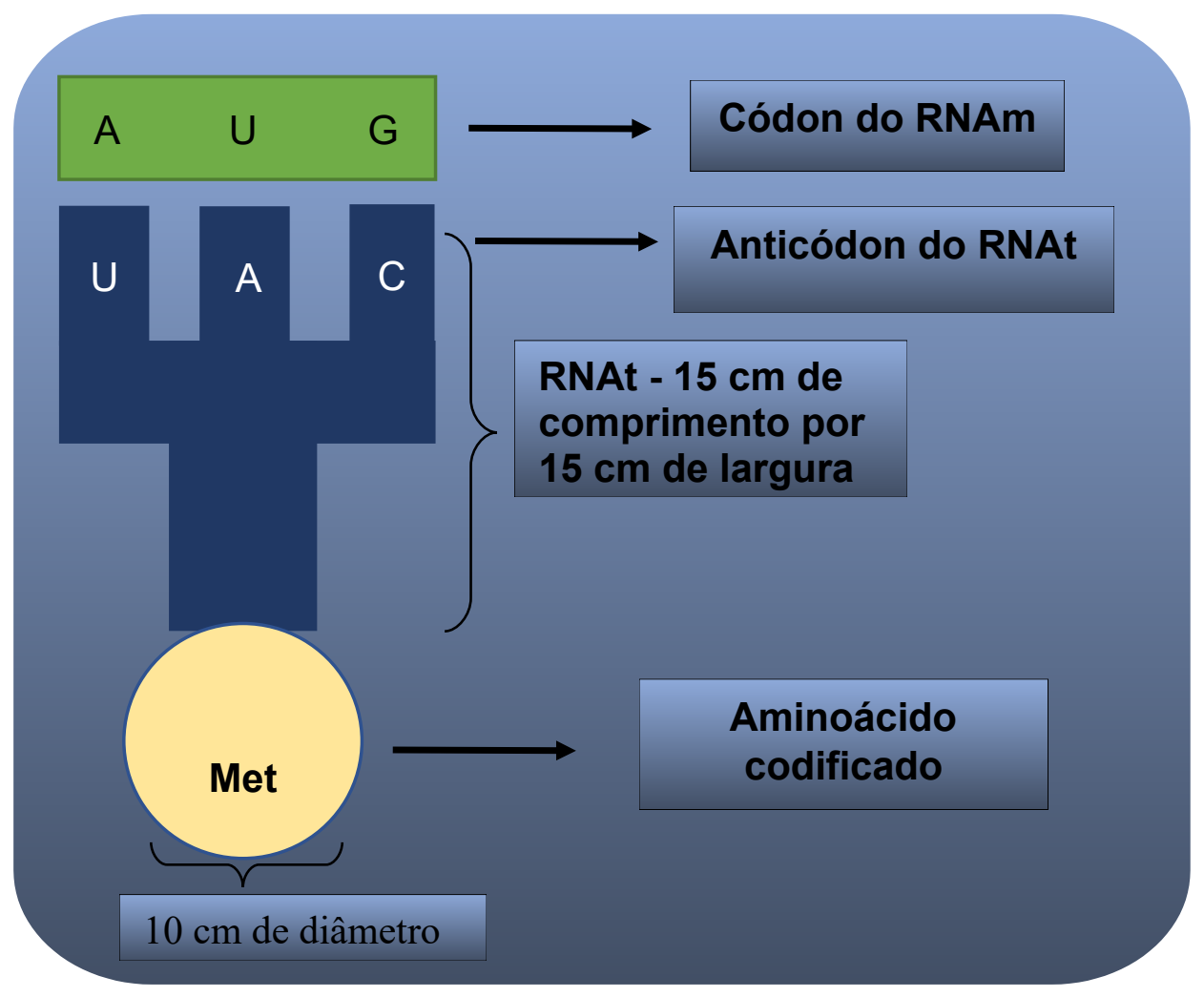

Figura 7 - Representação do primeiro RNAt com o anticódon, sequência do RNAm e o aminoácido codificado. Fonte: Elaborada pelos autores.

O ribossomo deverá ser confeccionado em EVA no formato clássico apresentado pelos livros didáticos do ensino médio. Pode-se utilizar as seguintes medidas: $25 \mathrm{~cm}$ de comprimento total, $22 \mathrm{~cm}$ a largura da subunidade maior $(60 \mathrm{~S})$ e $18 \mathrm{~cm}$ a largura da subunidade menor (40 S). Realizar um recorte no formato de um retângulo na subunidade ribossomal $40 \mathrm{~S}$ para a passagem da fita de RNAm, a qual desliza enquanto suas trincas são lidas e os aminoácidos incorporados ao polipeptídio. A Figura 8 apresenta o modelo sugerido. 


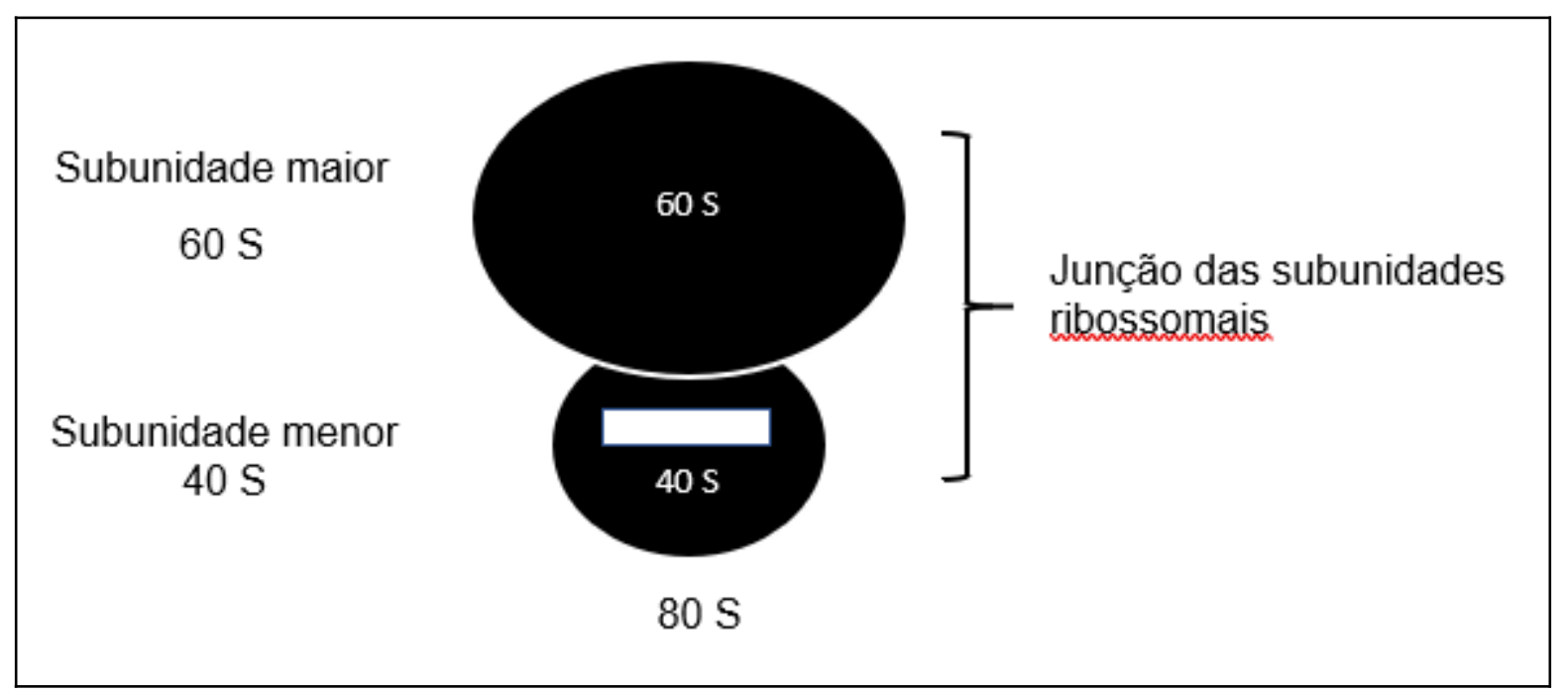

Figura 8. Representação de ribossomo de eucariotos. Fonte: Elaborada pelos autores.

Os aminoácidos, por sua vez, deverão ser confeccionados em EVA na forma circular, com diâmetro de $10 \mathrm{~cm}$ e em cores variadas, contendo as diferentes siglas que os identifica. Observação: confeccionar os aminoácidos que se repetem. A Figura 9 apresenta este processo.

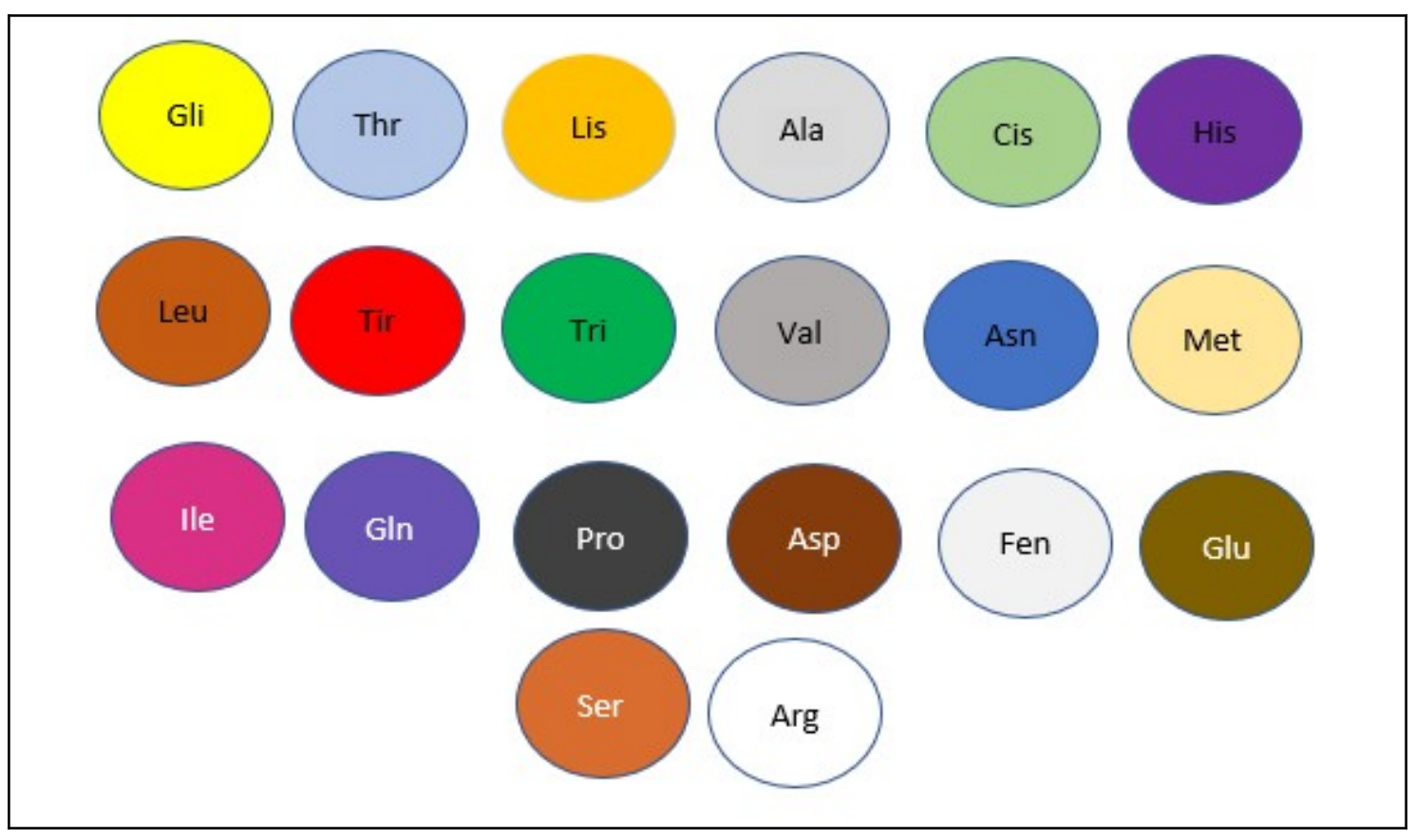

Figura 9. Representação dos aminoácidos. Fonte: Elaborada pelos autores. 
Abaixo segue a tabela do código genético para ser impressa e entregue às equipes para que elas possam consultar os códons e identificar os aminoácidos.

Tabela 1 - Símbolos dos códigos genéticos e seus respectivos aminoácidos.

\begin{tabular}{|c|c|c|c|c|c|c|}
\hline (extr. 5') & $\mathbf{U}$ & C & A & G & (extr. 3') & $\begin{array}{l}\text { Confira as siglas dos } 20 \text { aminoáci- } \\
\text { dos }\end{array}$ \\
\hline \multirow{4}{*}{$\mathbf{U}$} & $\begin{array}{l}\text { UUU } \\
\text { Phe }\end{array}$ & $\begin{array}{l}\text { UCU } \\
\text { Ser }\end{array}$ & $\begin{array}{l}\text { UAU } \\
\text { Tyr }\end{array}$ & $\begin{array}{l}\text { UGU } \\
\text { Cys C }\end{array}$ & $\mathbf{U}$ & $\begin{array}{l}\text { (Gly, Gli) - Glicina - (Thr, The) - } \\
\text { Treonina - (Lys, Lis) - Lisina }\end{array}$ \\
\hline & $\begin{array}{l}\text { UUC } \\
\text { Phe }\end{array}$ & $\begin{array}{l}\text { UCC } \\
\text { Ser }\end{array}$ & $\begin{array}{l}\text { UAC } \\
\text { Tyr }\end{array}$ & $\begin{array}{l}\text { UGC } \\
\text { Cys C }\end{array}$ & C & \\
\hline & $\begin{array}{l}\text { UUA } \\
\text { Leu }\end{array}$ & $\begin{array}{l}\text { UCA } \\
\text { Ser }\end{array}$ & $\begin{array}{l}\text { UAA } \\
\text { stop }\end{array}$ & $\begin{array}{l}\text { UGA } \\
\text { stop }\end{array}$ & A & $\begin{array}{l}\text { (Ala) - Alanina - (Cys, Cis) - Cisteí- } \\
\text { na - (His)- Histidina }\end{array}$ \\
\hline & $\begin{array}{l}\text { UUG } \\
\text { Leu }\end{array}$ & $\begin{array}{l}\text { UCG } \\
\text { Ser }\end{array}$ & $\begin{array}{l}\text { UAG } \\
\text { stop }\end{array}$ & $\begin{array}{l}\text { UGG } \\
\text { Trp }\end{array}$ & G & \\
\hline \multirow{4}{*}{ C } & $\begin{array}{l}\text { CUU } \\
\text { Leu }\end{array}$ & $\begin{array}{l}\text { CCU } \\
\text { Pro }\end{array}$ & $\begin{array}{l}\text { CAU } \\
\text { His }\end{array}$ & $\begin{array}{l}\text { CGU } \\
\text { Arg }\end{array}$ & $\mathbf{U}$ & $\begin{array}{l}\text { (Leu) - Leucina - (Tyr, Tir) -Tirosina } \\
\text { - (Trp, Tri)- Triptofano }\end{array}$ \\
\hline & $\begin{array}{l}\text { CUC } \\
\text { Leu }\end{array}$ & $\begin{array}{l}\text { CCC } \\
\text { Pro }\end{array}$ & $\begin{array}{l}\text { CAC } \\
\mathrm{His}\end{array}$ & $\begin{array}{l}\text { CGC } \\
\text { Arg }\end{array}$ & C & \\
\hline & $\begin{array}{l}\text { CUA } \\
\text { Leu }\end{array}$ & $\begin{array}{l}\text { CCA } \\
\text { Pro }\end{array}$ & $\begin{array}{l}\text { CAA } \\
\text { GIn }\end{array}$ & $\begin{array}{l}\text { CGA } \\
\text { Arg }\end{array}$ & A & $\begin{array}{l}\text { (Val) - Valina - (Asn) - Asparagina - } \\
\text { (Met) - Metionina }\end{array}$ \\
\hline & $\begin{array}{l}\text { CUG } \\
\text { Leu }\end{array}$ & $\begin{array}{l}\text { CCG } \\
\text { Pro }\end{array}$ & $\begin{array}{l}\text { CAG } \\
\text { GIn }\end{array}$ & $\begin{array}{l}\text { CGG } \\
\text { Arg }\end{array}$ & G & \\
\hline \multirow{4}{*}{ A } & $\begin{array}{l}\text { AUU } \\
\text { lle }\end{array}$ & $\begin{array}{l}\text { ACU } \\
\text { Thr }\end{array}$ & $\begin{array}{l}\text { AAU } \\
\text { Asn }\end{array}$ & $\begin{array}{l}\text { AGU } \\
\text { Ser }\end{array}$ & $\mathbf{U}$ & (Ile) - Isoleucina - (GIn) - Glutamina \\
\hline & $\begin{array}{l}\text { AUC } \\
\text { lle }\end{array}$ & $\begin{array}{l}\text { ACC } \\
\text { Thr }\end{array}$ & $\begin{array}{l}\text { AAC } \\
\text { Asn }\end{array}$ & $\begin{array}{l}\text { AGC } \\
\text { Ser }\end{array}$ & C & \\
\hline & $\begin{array}{l}\text { AUA } \\
\text { lle }\end{array}$ & $\begin{array}{l}\text { ACA } \\
\text { Thr T }\end{array}$ & $\begin{array}{l}\text { AAA } \\
\text { Lys }\end{array}$ & $\begin{array}{l}\text { AGA } \\
\text { Arg }\end{array}$ & A & $\begin{array}{l}\text { (Pro) - Prolina - (Asp) - Aspartato ou } \\
\text { Ácido aspártico }\end{array}$ \\
\hline & $\begin{array}{l}\text { AUG } \\
\text { Met } \\
\text { Start }\end{array}$ & $\begin{array}{l}\text { ACG } \\
\text { Thr T }\end{array}$ & $\begin{array}{l}\text { AAG } \\
\text { Lys }\end{array}$ & $\begin{array}{l}\text { AGG } \\
\text { Arg }\end{array}$ & G & \\
\hline \multirow{4}{*}{ C } & $\begin{array}{l}\text { GUU } \\
\text { Val V }\end{array}$ & $\begin{array}{l}\text { GCU } \\
\text { Ala }\end{array}$ & $\begin{array}{l}\text { GAU } \\
\text { Asp }\end{array}$ & $\begin{array}{l}\text { GGU } \\
\text { Gly }\end{array}$ & $\mathbf{U}$ & $\begin{array}{l}\text { (Phe ou Fen) - Fenilalanina - (Glu) - } \\
\text { Glutamato ou Ácido glutâmico }\end{array}$ \\
\hline & $\begin{array}{l}\text { GUC } \\
\text { Val V }\end{array}$ & $\begin{array}{l}\text { GCC } \\
\text { Ala }\end{array}$ & $\begin{array}{l}\text { GAC } \\
\text { Asp }\end{array}$ & $\begin{array}{l}\text { GGC } \\
\text { Gly }\end{array}$ & C & \\
\hline & $\begin{array}{l}\text { GUA } \\
\text { Val V }\end{array}$ & $\begin{array}{l}\text { GCA } \\
\text { Ala }\end{array}$ & $\begin{array}{c}\text { GAA } \\
\text { Glu }\end{array}$ & $\begin{array}{l}\text { GGA } \\
\text { Gly }\end{array}$ & A & Serina (Ser) - (Arg)- Arginina \\
\hline & $\begin{array}{l}\text { GUG } \\
\text { Val V }\end{array}$ & $\begin{array}{l}\text { GCG } \\
\text { Ala }\end{array}$ & $\begin{array}{c}\text { GAG } \\
\text { Glu }\end{array}$ & $\begin{array}{l}\text { GGG } \\
\text { Gly }\end{array}$ & G & \\
\hline
\end{tabular}

Fonte: Elaborada pelos autores.

\subsection{Dinâmica do jogo}

O objetivo do jogo é reforçar a informação aos alunos de que o códon é constituído por uma trinca de nucleotídeos e que essa trinca codifica os aminoácidos. Além disso, a prática do jogo tem potencial para permitir aos alunos compreenderem o papel dos três diferentes tipos de RNAs no processo de tradução [o RNA mensageiro (RNAm), o RNA transportador (RNAt) e o RNA ribossômico (RNAr)], aprenderem a consultar a tabela do 
código genético, além de exercitarem o processo de montagem das suas proteínas, de acordo com o gene recebido no início da prática.

Sugere-se que os estudantes sejam divididos em três equipes: Equipe 1, Equipe 2 e Equipe 3 (outras nomenclaturas poderão ser adotadas pelo professor de maneira a motivar os alunos para a prática). Contudo, orienta-se para que cada equipe deverá ser composta por um mínimo de 11 alunos; os motivos estarão explicados abaixo.

As equipes receberão uma sequência de DNA - gene que contém a informação para transcrever o RNA mensageiro (RNAm) e traduzir essa informação em proteína. A sequência de nucleotídeos do gene deverá ser impressa em uma folha de sulfite $A 4$, com letras grandes para facilitar a visualização de todos os alunos. O RNAm será entregue em uma fita de cetim em branco, ou seja, sem nada escrito. As equipes serão orientadas a transcrever os códons nessa fita e passar pelo ribossomo para a leitura.

Em cada uma das equipes, o professor orientará para que dez (10) alunos de cada equipe deverão ser recrutados para representarem os RNAs transportadores (RNAt). No outro extremo da sala deverá ser colocada uma caixa com os diferentes tipos de aminoácidos; caberá a esses alunos (RNAt) procurar na caixa o aminoácido corresponde ao seu códon e levar até o ribossomo da sua equipe. Após o primeiro aluno ter inserido o primeiro aminoácido, será a vez do segundo aluno (segundo RNAt) correr até a caixa, procurar o segundo aminoácido, trazê-lo até a sua equipe e encaixá-lo no ribossomo. A corrida dos alunos acontecerá em sequência até o décimo aluno da equipe; no $11^{\circ}$ é um códon de parada.

A equipe vencedora será aquela que formar o RNAm corretamente, colocar todos os anticódons corretamente no RNAt, fazer o pareamento correto (códon e anticódon) e a sequência correta dos aminoácidos até o códon de parada (Stop códon) no menor tempo.

Caso a equipe forme o RNA e proteína com erros, o professor pode trabalhar o conceito de mutação e a sua implicação na função das proteínas. Pode relacionar a ação da insulina na homeostase da glicose e falhas na sua ação pode levar o indivíduo a um quadro de diabetes melitos. Pode discutir a mutação que ocorre no gene da hemoglobina que leva a uma modificação da estrutura primária e consequentemente a alteração da sua função com o desenvolvimento da anemia falciforme. No caso do hormônio do crescimento $(\mathrm{GH})$ é possível realizar uma discussão sobre a síndrome de resistência ao $\mathrm{GH}$ causada por uma mutação no receptor de $\mathrm{GH}$ ocasionando baixa estatura. Reforçar com os alu- 
nos a importância das proteínas, suas principais funções e deixar claro que são elas que executam as diferentes funções celulares.

\subsection{Apresentação do material confeccionado}

Essa proposta pedagógica foi pensada para a modalidade presencial com atividades interativas e as figuras 10,11, 12, 13 e 14, a seguir, apresentam o material didático confeccionado pelos pesquisadores e por alunos voluntários. Dessa forma, as figuras citadas apresentarão uma simulação da aplicação da atividade.

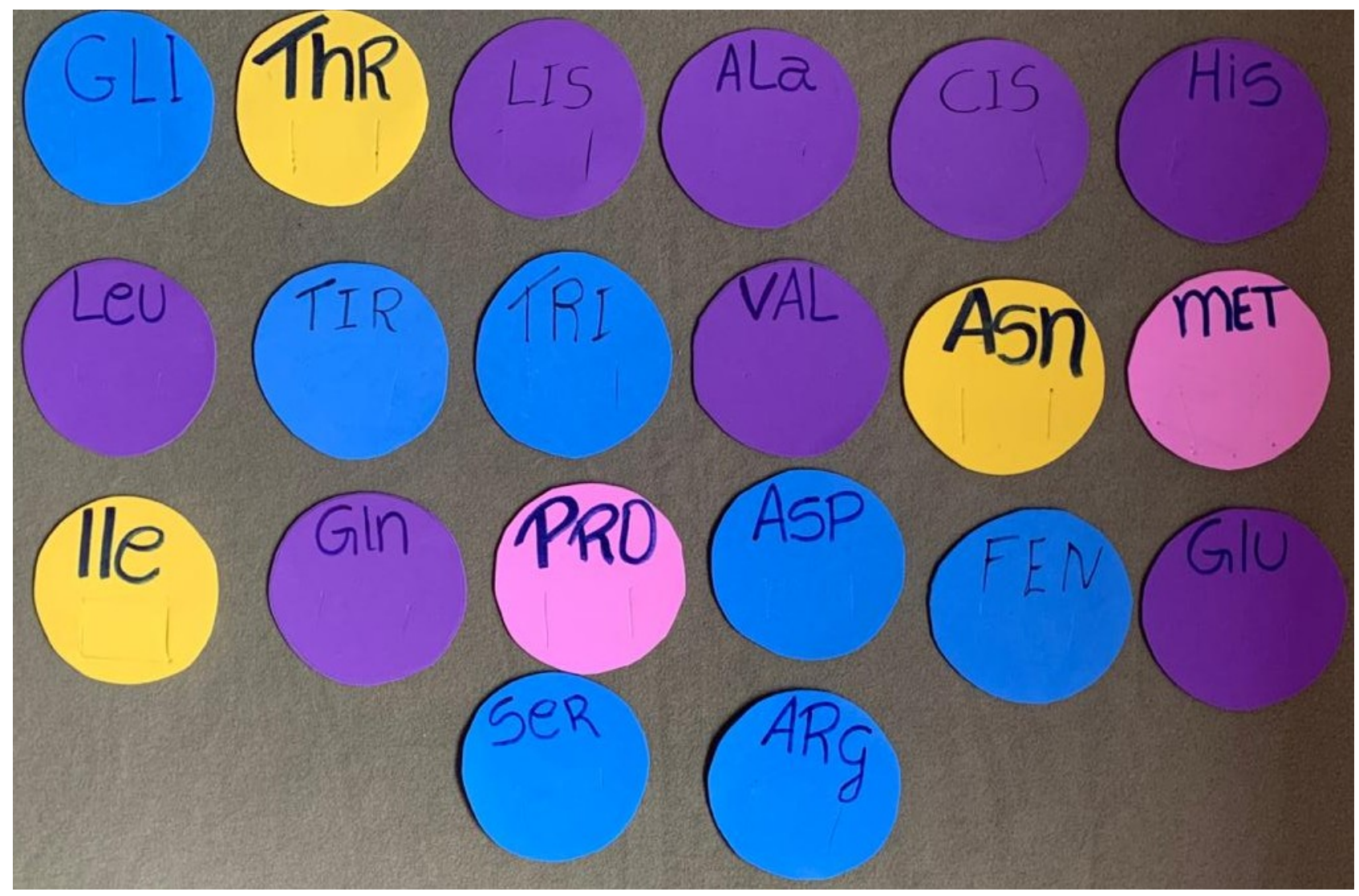

Figura 10. Representação dos aminoácidos confeccionados em EVA. Fonte: Arquivo fotográfico dos autores. 


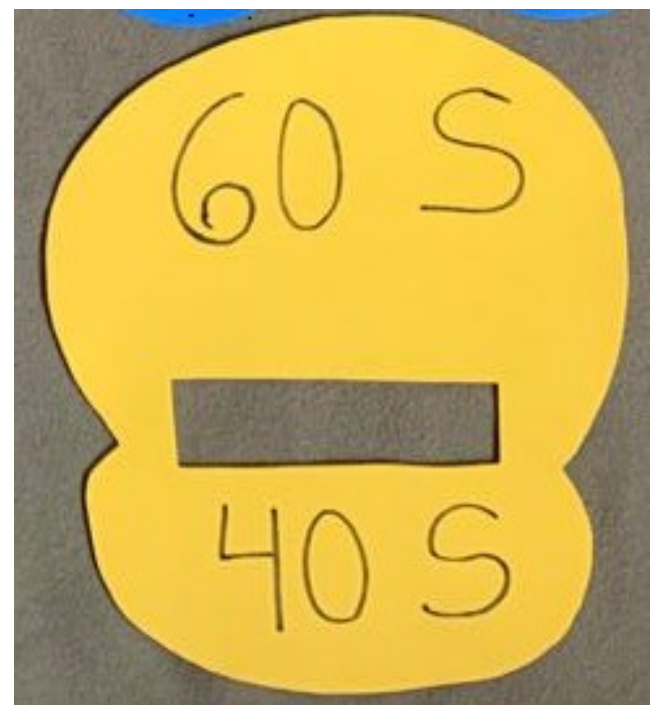

Figura 11. Representação do ribossomo confeccionado em EVA. Fonte: Arquivo fotográfico dos autores.

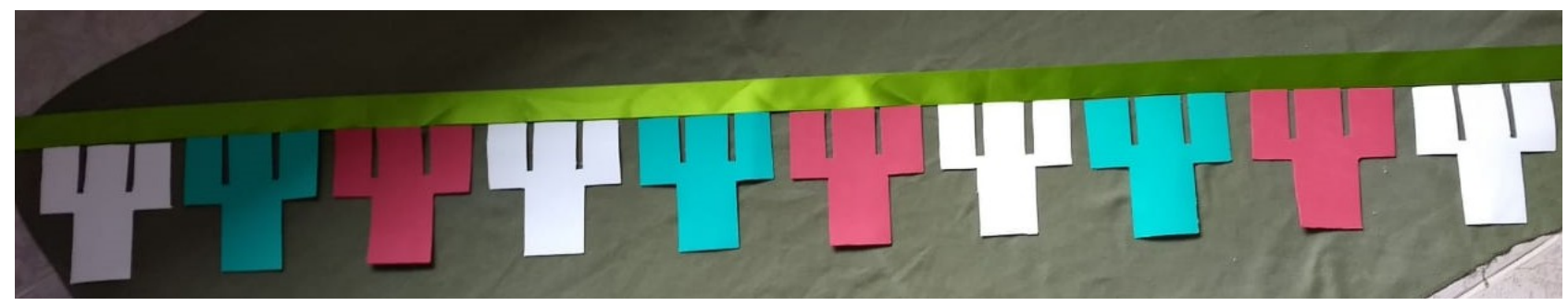

Figura 12. Representação da fita de cetim representando o RNAm e os RNAt confeccionados em EVA. Fonte: Arquivo fotográfico dos autores.

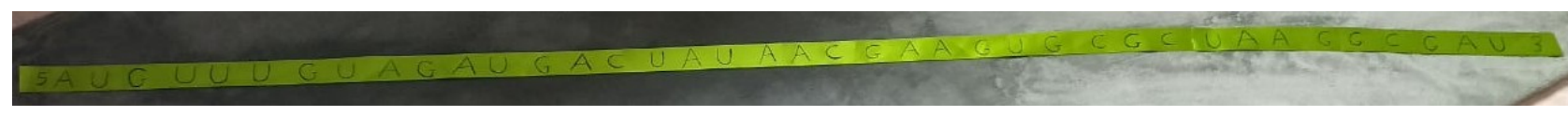

Figura 13. Representação da fita de RNAm transcrito com os códons. Fonte: Arquivo fotográfico dos autores.

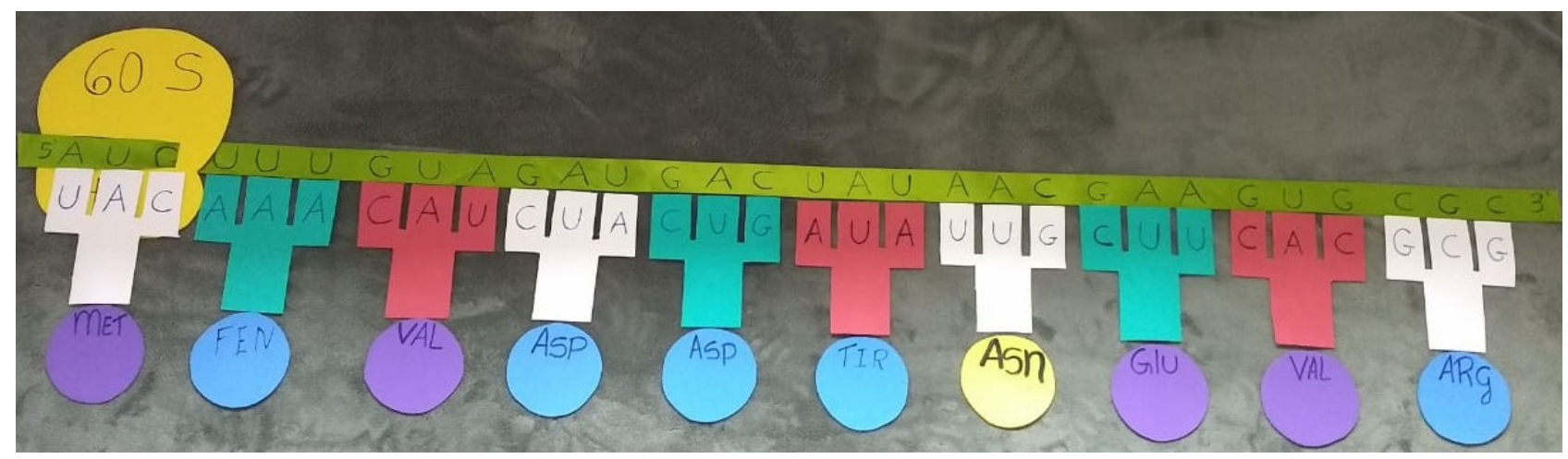

Figura 14. Representação do ribossomo, da fita de RNAm, os RNAt e aminoácidos na sequência correta da proteína. Fonte: Arquivo fotográfico dos autores.

\section{Considerações finais}

O DNA é a molécula que contém a informação genética da vida. Para o aluno compreender como essa informação é armazenada, transferida e expressa nos organismos, é 
indispensável que ele compreenda os mecanismos moleculares de replicação, transcrição e tradução. Nesse sentido, apresentamos essa ferramenta pedagógica lúdica e interativa que permite que o aluno reforce os conteúdos trabalhados de forma teórica pelo professor e que tem potencial para contribuir com o alcance da efetiva aprendizagem.

Essa proposta pedagógica vem ao encontro das competências e habilidades preconizadas pela Base Nacional Comum Curricular (BNCC), tais como: mobilização de conhecimentos, habilidades (práticas, cognitivas e socioemocionais) e o entendimento de fenômenos e processos relacionados ao mundo natural [19].

Também é importante ressaltar a potencialidade da interatividade proposta para o trabalho em equipe unindo os alunos e o professor, o investimento no exercício da argumentação e gerenciamento de conflitos pelos próprios estudantes na confecção e resolução da atividade proposta. Destaca-se também a possibilidade de organizar um planejamento interdisciplinar que envolva os professores de Biologia e Matemática; este último poderia trabalhar conceitos de raio, diâmetro, área de figuras planas, dentre outras possibilidades.

\section{Referências bibliográficas}

[1] de Carvalho J.C.Q, Beltramini LM, Abel, L.D.S, Bossolan N.R.S. "Sintetizando Proteínas", o jogo: proposta e avaliação de uma ferramenta educacional. Revista de Ensino de Bioquímica. v. 12. n.1. 2014

[2] Weyh A, Carvalho I.G.B, Garnero A. del V. Twister Proteico: uma ferramenta lúdica envolvendo a síntese de proteínas. Revista de Ensino de Bioquímica. v. 13. n.1. 2015

[3] Sturges D, Maurer T.W, Cole O. Understanding protein synthesis: a role-play approach in large undergraduate human anatomy and physiology classes. Adv Physiol Educ 33: 103-110. 2009.

[4] Templin M.A, Fetters M.K. A working model of proteins synthesis using Lego® building blocks. Am Biol Teach; 64(9): 673-678. 2002.

[5] Camargo S.S, Infante-Malachias M.E. A genética humana no Ensino Médio: algumas propostas. Genética na Escola. 2007; 2(1): p. 14-16.

[6] da Silva M.I, Pinheiro S.B, Mendes S.A.B.A, Campelo T.W.M, dos Santos Y.V.S, Gross M.C, Rodrigues D.P. Jogo AminoUNO: Uma Ferramenta Alternativa Para O Ensino Da Síntese De Proteínas No Ensino Médio. Revista de Ensino de Bioquímica. v. 12. n.1. 2013.

[7] Gomes R.R, Friedrich M. A Contribuição dos jogos didáticos na aprendizagem de conteúdos de Ciências e Biologia. In: EREBIO,1, Rio de Janeiro, 2001, Anais..., Rio de Janeiro, 2001, p.389-392.

[8] Pereira H.A.B.S, Pereira T.M, Magalhães A.C. Síntese Proteica "O Jogo" Journal of Biochemistry Education. v. 15, Esp / 2017.

[9] Cheng M.T, Annetta L. Students' learning outcomes and learning experiences through playing a Serious Educational Game. Journal of Biological Education. 2012.

[10] Cheng M.T, She H.-C., \& Annetta, L. A. (2014a). Game immersion experience: Its hierarchical structure and impact on game-based science learning. Journal of Computer Assisted learning. 2014. 
[11] Almeida M.T.P de. Jogos Divertidos E Brinquedos Criativos. Petrópolis/RJ: Vozes, 2004.

[12] Grando R.C. O Jogo: suas Possibilidades Metodológicas no Processo Ensino-Aprendizagem da Matemática. Dissertação de Mestrado. Campinas, SP. Faculdade de Educação, Universidade Estadual de Campinas, Campinas, SP, 1995. Disponível em:

http://repositorio.unicamp.br/jspui/handle/REPOSIP/253786. Acesso em 15 mar. 2020.

[13] Prensky M. Teaching digital natives: partnering for real learning. Thousand Oaks, CA: Corwin;2010.

[14] Freeman $S$ et al. Active learning increases student performance in science, engineering and mathematics. PNAS;111(23): 8410-8415. 2014.

[15] Cortelazzo A.L, Fiala D.A.S, Piva Jr D, Panisson L, Rodrigues M.R.J.B. Metodologias ativas e personalizadas de aprendizagem: para refinar seu cardápio metodológico. $1^{\mathrm{a} e d}$. Rio de Janeiro: Alta Books, 2018.

[16] Miranda S. No Fascínio do jogo, a alegria de aprender. In: Ciência Hoje, v.28, p. 64-66. 2001.

[17] Dohme V. Atividades lúdicas na educação: o caminho de tijolos amarelos do aprendizado. 4. ed. Petrópolis, RJ: Vozes, 2008.

[18] Zuanon Á.C.A, Diniz RHS, Nascimento LH. Construção de jogos didáticos para o ensino de Biologia: um recurso para integração dos alunos à prática docente. R. B. E. C. T. v. 3, n. 3, set./dez. 2010

[19] BASE NACIONAL COMUM CURRICULAR: Educação é a base. Versão Final. Ministério da Educação: Brasília, 2017. 